\title{
El pentecostalismo en la novela Himno del ángel parado en una pata, de Hernán Rivera Letelier*
}

\author{
Miguel Ángel Mansilla ${ }^{a}$
}

Instituto de Estudios Internacionales, INTE, de la Universidad Arturo Prat, Chile http://orcid.org/0000-0001-5684-0787

\section{Luis Orellana Urtubia}

Instituto de Estudios Internacionales, INTE, de la Universidad Arturo Prat, Chile http://orcid.org/0000-0001-7411-2126

\section{Nicolás Panotto}

Instituto de Estudios Internacionales, INTE, de la Universidad Arturo Prat, Chile http://orcid.org/0000-0002-0513-7175

RECIBIDO: 04-02-19. APROBADO: 12-05-19

Resumen: El presente artículo aborda la cultura pentecostal a partir de un análisis de la novela de Rivera Letelier, Himno del ángel parado en una pata, ambientada en la en la década de 1960, en la zona minera del salitre, en Antofagasta. Su principal objetivo es analizar cómo la miseria, la sobrevivencia, el mal, el dolor y el sufrimiento humano, característicos de las dinámicas sociales de la época en dicha área, y específicamente en los imaginarios plasmados en la literatura de entonces, son asumidos y resignificados desde una perspectiva religiosa, concretamente pentecostal. En el abordaje teórico se recurrió a los estudios de Clifford Geertz, para quien uno de los roles de la religión es asignar sentido al dolor y al sufrimiento en cuanto experiencias sociales. En este sentido, el pentecostalismo no resuelve problemas, sino que les asigna sentido, valor y significado.

El artículo está dividido en tres grandes apartados: (1) Tiempo y espacio cúltico. (2) La construcción de lo masculino y lo femenino. (3) El problema del mal y el dolor. En el primero, damos cuenta de la relación entre vivienda y templo pentecostal como dos construcciones precarias, donde el templo es en un espacio flexible condicionado por el culto, un tiempo y un espacio, que brinda libertad a las emociones religiosas. Luego nos referimos a la tensión de siempre entre las exigencias institucionales frente a lo femenino y lo masculino, pero en la que los sujetos finalmente deciden y encuentran sus espacios de libertad para flexibilizar las demandas religiosas; $y$ pese a los controles sobre todo en relación con el cuerpo, que pesan sobre las mujeres, ellas logran sortearlos. Por último, en relación con el mal y el dolor destacamos

\footnotetext{
*Artículo de investigación.
}

${ }^{a}$ Autor de correspondencia. Correo electrónico: mansilla.miguel@gmail.com 
las distintas ritualidades que el autor muestra que los pentecostales realizan, como estrategias para disminuir los efectos caótico en la vida del creyente, sobre todo lo relacionado con la enfermedad y la muerte.

Palabras Clave: Religión; evangélicos; pentecostal; culto; cultura; género; mujer; hombre; el mal; el dolor.

\section{The (Un)veiled Pentecostal Culture in the Saltpetre Camps. Pentecostalism in the novel Hymn of the Angel Standing on One Leg, by Hernan Rivera Letelier}

Abstract: This article deals with Pentecostal culture based on an analysis of Rivera Letelier's novel, Hymn of the Angel Standing on One Leg, set in in the 1960s, the saltpeter mining area, in Antofagasta, Chile. Its main objective is to analyze how the concepts of misery, survival, evil, pain and human suffering-characteristic of the social dynamics of the time in that region, and more specifically of the imaginaries embodied in literature-are assumed and resignified from a religious perspective, namely, from a Pentecostal perspective. The theoretical approach is based in the studies of Clifford Geertz, who considers that one of the roles of religion is to assign meaning to pain and suffering as social experiences. In this sense, Pentecostalism does not solve problems, but rather assigns meaning, value and significance to them.

This article is divided into three main sections: (1) Time and cultural space. (2) The construction of the masculine and the feminine. (3) The problem of evil and pain. In the first section, we will analyze the relationship between housing and Pentecostal temple as two precarious constructions, where the last one is a flexible space conditioned by worship, as well as by a time and space that provides freedom to religious emotions. Afterword, we refer to the tension between the institutional demands as opposed to the feminine and the masculine, where the subjects finally decide and find their spaces of freedom to make the religious demands more flexible; all of this, despite the mechanisms of control, especially refered to the body, that weigh mostly on women. Finally, in relation to evil and pain, we highlight the different rituals that the author presents, that the Pentecostals carry out as strategies to diminish the chaotic effects in the life of the believer, especially those related to illness and death.

Key Words: Religion; Evangelicals; Pentecostal; Worship; Culture; Gender; Woman; Man; Evil; Pain.

\section{CÓMO CITAR:}

Mansilla, Miguel Ángel; Luis Orellana Urtubia; y Nicolás Panotto. "El pentecostalismo en la novela Himno del ángel parado en una pata, de Hernán Rivera Letelier". Theologica Xaveriana (2021): 1-34. https://doi.org/10.11144/javeriana.tx71.pnhapp

\section{ReCONOCIMIENTO}

Este artículo se ubica en el proyecto de investigación N. ${ }^{\circ} 1180924$, "La fe mueve fronteras: comunidades evangélicas, movilidad circulatoria y resignificación étnica, nacional y religiosa de los indígenas andinos en las fronteras del norte de Chile con Perú y Bolivia”, proyecto financiado por la Comisión Nacional de Investigación Científica y Tecnológica, Conicyt, de Chile. 


\section{Introducción}

El pentecostalismo -que nació en 1909, en el centro y centro sur de Chile (Valparaíso, Santiago y Concepción) - se extendió tempranamente a Antofagasta e Iquique, ciudades ubicadas en el desierto del país, donde se localizan los centros mineros del salitre, cuyo auge industrial se ubica entre 1880 y 1930, cuando se expandió, hasta el cierre de la última Oficina salitrera, en $1978^{1}$.

El pentecostalismo llegó a esta zona de la mano de Adela Gómez, misionera y posteriormente Pastora Diaconisa, en 1922. Ella trabajó en Tarapacá, primero en la Oficina de Buenaventura y luego en Alianza. Hay correspondencia de informes sobre el trabajo que realizó desde 1923. El 20 de abril de 1930 fue ordenada Diaconisa y finalmente fue reconocida como Pastora Probando, en $1938^{2}$.

También hay registro de que Adela Gómez estuvo predicando en la Salitrera Chacabuco (Antofagasta) porque ahí se convirtió Máximo Montecinos, quien la reconoció como predicadora en su conversión. Después, en 1935, Montesinos se instaló en la Oficina de Humberstone (Pozo Almonte, Tarapacá), y en 1938 fue nombrado Pastor Probando. Luego se radicó en Iquique, y pastoreó hasta 1955. El pentecostalismo se instaló en la ciudad de Antofagasta, en 1930, y en Iquique lo hizo dos décadas más tarde.

Cuando el pentecostalismo llegó a la zona salitrera, en la década de los años 20, la masacre de la Escuela Santa María, en $1907^{3}$, aún estaba en el recuerdo de las personas, tanto de trabajadores como administradores. Por ello, los administradores estaban atentos a cualquier manifestación de protesta o levantamiento. En este sentido es claro el relato de una comunidad pentecostal del lugar:

El martes 20 de octubre (1936) en la Oficina Bellavista [Tarapacá...] iban varios hermanos a una reunión con un grupo de niños que cantaban alabanzas al Señor. Tenían que pasar al frente de la casa del subdelegado y lo hicieron cantando himnos. Le pareció muy mal y habló por teléfono a los carabineros, diciéndoles "que un grupo de comunistas habían pasado por su casa cantando la Marsellesa". Llegaron los carabineros y se dieron cuenta de que no eran "comunistas", sino evangélicos, los policías se llevaron algunos testamentos e himnarios para comprobar el asunto ante delegado. ${ }^{4}$

\footnotetext{
${ }^{1}$ Véase a González, Hombres y mujeres de la pampa. Tarapacá en el ciclo de expansión del salitre.

${ }^{2}$ Mansilla y Orellana, "Haciendo memoria de líderes religiosas olvidadas. El reconocimiento póstumo del trabajo de las pastoras en el pentecostalismo chileno", 77-113.

${ }^{3} \mathrm{Al}$ respecto se puede revisar, en Archivo Nacional de Chile, "21 de diciembre de 1907. Matanza de la Escuela de Santa María de Iquique en 1907".

${ }^{4}$ Véase la revista Fuego de Pentecostés 98 (1936): 7.
} 
En la década de los 60, las oficinas salitreras estaban en franco declive. Pese a ello, y en ese contexto, encontramos pentecostales a quienes describe Rivera Letelier en la Salitrera Algorta (Antofagasta), en el libro Himno del ángel parado en una pata. En este autor encontramos dos influencias:

- $\quad$ El libro La sangre y la esperanza de Nicomedes Guzmán5. En el caso de Rivera Letelier, la historia es contada por un niño, Hildebrando del Carmen (de trece años), cuyas experiencias religiosas ocupan todo el libro. En el caso de Guzmán, se trata del niño Enrique Quilodrán, quien relata y describe el culto pentecostal desde su habitación.

- Las memorias de la adolescencia: las habitaciones miserables describen la estrategia de los pobres, ya sea en el norte o en centro de Chile, formas similares al "forrar la perforada pieza con papel de diario", dice Rivera Letelier.

No pretendemos hacer un análisis de la obra rivereana, que ha sido analizada de manera exhaustiva por otros autores ${ }^{6}$; tampoco estudiar la totalidad del libro Himno del ángel parado en una pata, ya que de él también encontramos revisiones detalladas. Nos interesa, más bien, abordar la cultura pentecostal en el contexto de una zona minera, en este caso el salitre, tal como el autor muestra y lo representa en la novela: algo que no ha sido investigado hasta el momento.

¿Por qué es importante estudiar la cultura pentecostal en el contexto de una novela ubicada en una zona salitrera? Sobre la historia del salitre y del salitrero se han escrito innumerables obras'; y también sobre pentecostalismo ${ }^{8}$; sin embargo, la dimensión simbólica del modelo industrial y fabril salitrero -así como su conexión con el pentecostalismo como expresión religiosa local- han sido desatendidos. Al comprender que una novela es una ficción histórica y una historización ficcional de creencias, prácticas, ritos y mitos religiosos, en este caso los pentecostales, en un contexto industrial en crisis, es significativo ver en dónde se enfrenta y cómo se confrontan la crisis económica y la geografía escabrosa a partir de una "religión de los pobres".

\footnotetext{
${ }^{5}$ Véase a Guzmán, La sangre y la esperanza.

${ }^{6}$ Maíz, "La narrativa de Rivera Letelier: Los signos de la escasez y la abundancia compensatoria”, 157-169; Ostria, "La identidad pampina en Rivera Letelier", 67-79; Blaustein, "Incursiones en un texto amistoso: Himno del ángel parado en una pata, de Hernán Rivera Letelier", 143-161; Bravo, "Literatura y contraemplazamientos: vigilancia, heterotopía, traición y alteridad literaria en Chile... a partir de la ficción narrativa de Hernán Rivera Letelier".

${ }^{7}$ Véase a González, Hombres y mujeres de la pampa. Tarapacá en el ciclo de expansión del salitre.

${ }^{8}$ Mansilla, "Pentecostalismo y ciencias sociales reflexión en torno a las investigaciones del pentecostalismo chileno (1968-2008)”, 21-42.
} 
Cabe preguntarnos, entre muchos otros interrogantes: ¿Cómo se asume la miseria, el trabajo de sobrevivencia, el mal y el sufrimiento humano en la novela? Para eso recurrimos a Clifford Geertz' quien señala el rol de la religión en los siguientes términos:

...paradójicamente no es el de evitar el sufrimiento sino el de cómo sufrir, de cómo hacer de un dolor físico, de una pérdida personal, de una derrota o de la impotente contemplación de la agonía de otra persona algo tolerable, soportable, algo, como solemos decir, sufrible. ${ }^{10}$

Al interesarnos por la cultura pentecostal descrita en una novela -como destaca Geertz-, "nos interesa la dimensión cultural del análisis religioso" ${ }_{11}$, es decir, la dimensión simbólica del pentecostalismo a partir de una construcción cultural (novela), que describe la cultura salitrera chilena inserta en el desierto. Más aún, esta lectura nos permitirá revisar las representaciones culturales en torno del pentecostalismo de aquel tiempo mediante un análisis literario, e indagar cómo la expresión religiosa pentecostal es capaz "de servir como fuente de concepciones generales, aunque distintivas del mundo, del yo y de las relaciones entre si” $^{\prime \prime 2}$ en un contexto de tensiones, crisis y pasajes permanentes, en una región que da cuenta de profundas dinámicas sociopolíticas y económicas a nivel nacional tendiente a mejorar condiciones de vida de los obreros.

El presente artículo lo dividimos en tres grandes apartados:

- Tiempo y espacio cúltico.

- La construcción de lo masculino y lo femenino.

- El problema del mal y el dolor.

En el primero damos cuenta de la relación entre vivienda y templo pentecostal como dos construcciones precarias, solo que el templo se constituía como espacio flexible condicionado por el culto, el tiempo y el espacio, que brindaba libertad a las emociones religiosa. En el segundo apartado nos referimos a la tensión existente entre las exigencias institucionales frente a lo femenino y lo masculino, en la que los sujetos finalmente deciden y encuentran sus espacios de libertad para flexibilizar las demandas religiosas. Por último, respecto del mal y el dolor destacamos las distintas

\footnotetext{
9 Véase a Geertz, La interpretación de las culturas.

${ }^{10}$ Ibíd., 100.

${ }^{11}$ Ibíd., 88.

${ }^{12}$ Ibíd., 106.
} 
ritualidades que el autor muestra que los pentecostales realizan, como estrategias para disminuir los efectos caóticos en la vida del creyente.

Las comunidades pentecostales fueron y son el punto de encuentro para un número importante de personas pobres que encuentran en el pentecostalismo un sentido al sinsentido de la vida. Tal es el espacio donde se desarrolló la cultura religiosa pentecostal. Por consiguiente, analizaremos cómo Rivera Letelier, en su novela Himno a un ángel parado en una pata, por medio de su protagonista, el adolescente Hidelbrando del Carmen, concibe lo pentecostal, que en esta obra aparece encarnado en la Iglesia Evangélica Pentecostal, en la Oficina Salitrera Algorta ${ }^{13}$.

\section{Tiempo y espacio cúltico}

Los pentecostales tienen una conocida expresión en relación con el culto: "Sabemos a la hora que comenzamos, pero no la hora en que terminamos". De este modo, todo espacio cultico se constituía en un tiempo catártico y extático en el cual se brindaba la libertad para orar, llorar, cantar, hablar en lenguas, imponer manos y danzar. En cuanto a los espacios cúlticos, cualquier lugar servía: un establo, el trabajo, la calle, en el hogar, etc.; porque ahí donde había dos o tres personas reunidas había un culto.

\section{Espacio cúltico: las casas-templo}

Clifford Geertz destaca que "el papel de la religión difiere en las diversas épocas, en los diversos individuos y en las diversas culturas" ${ }^{14}$. Esto supone que la religión es diferida por las condiciones geográficas y económicas. En nuestro caso, el sistema industrial salitrero es donde emergen o se da relevancia a algunos aspectos, por ejemplo, el desierto, instancias que el pentecostalismo -como otras religiones- utiliza para simbolizar las condiciones adversas de vida individual y social.

Las condiciones habitacionales de los obreros salitreros eran precarias, según lo destacado por González ${ }^{15}$, y en medio de esta precariedad habitacional, los pentecostales levantaron un templo.

Transformar las habitaciones de los creyentes en casas-templo era común en todo el pentecostalismo chileno, tal como describe Rivera -"la Iglesia Evangélica Pentecostal,

\footnotetext{
${ }^{13}$ Valga anotar, por último, que la Iglesia Evangélica Pentecostal, IEP, hunde sus raíces en el avivamiento pentecostal de 1909, en Valparaíso, y que en los años 60 disponía de varios grupos que estaban en pleno desarrollo en los sectores más pobres de las principales ciudades del norte de Chile (donde se ambienta la novela de Rivera Letelier).

${ }^{14}$ Geertz, La interpretación de las culturas, 122.

${ }^{15}$ González, Hombres y mujeres de la pampa. Tarapacá en el ciclo de expansión del salitre.
} 
a la que pertenecían sus padres cuyo culto oficiaba en la primera pieza de su casa"16-, y es destacado también por Guzmán. El fenómeno de las casas-templo respondía a la falta de templos y a los escasos recursos para construir recintos de reunión.

En tal sentido, para el creyente pentecostal, esta era una realidad significativa, ya que entre la precariedad de su vivienda y la precariedad del templo no había diferencia: ambos estaban en espacios de miseria. De igual modo, la casa-templo era un espacio naturalizado socialmente para la mujer de la época; también representaba un lugar de autonomía relativa, ya que había menos control por parte del pastor, por lo cual la mujer podía predicar con más libertad, así como lo hacía en la calle.

Rivera Letelier destaca esto en la vida de la familia de Hidelbrando, que vivió por años en el desierto, específicamente en la Salitrera Algorta, y luego se trasladó a la ciudad de Antofagasta, para habitar en una población marginal en condiciones de miseria:

Hidelbrando vivía en la temible población Lautaro [...] Su casa se levantaba en el patio de la Iglesia Evangélica Pentecostal (IEP). Se trataba de una casucha arrimada al muro posterior del templo, construida enteramente de tablas y latas, y dividida en dos por un tabique de sacos. ${ }^{17}$

Vivir al lado del templo era vivir gratis: estaba reservado a personas pobres o a algún feligrés de reconocida consagración religiosa y con referencia o credenciales de autorización del pastor. No obstante, la pobreza era notoria, ya que Hidelbrando tuvo varios trabajos: como vendedor de empanadas, de pan amasado y del periódico. Esto es algo característico de la niñez en condiciones de pobreza: la precoz inserción laboral; pero como "la religión, al fusionar ethos y cosmovisión, confiere a una serie de valores sociales" ${ }^{18}$, de la misma manera el pentecostalismo, en este caso la Iglesia Evangélica Pentecostal, brindó al creyente una cosmovisión penosa frente a la vida, al mundo, al trabajo o la pobreza.

Fue la modalidad de templo-casa la que hizo crecer al pentecostalismo, sobre todo, por su matiz mitificado: no solo llevaron los pobres a los templos, sino también llevaron el templo hasta los pobres. De este modo, las condiciones de miseria permitieron sacralizar la precariedad de los templos, combinando los mitos de las comunidades desheredadas de los relatos bíblicos con los ritos pentecostales, y por consiguiente "en los mitos y ritos sagrados los valores se pintan, como condiciones

\footnotetext{
${ }^{16}$ Rivera, Himno del ángel parado en una pata, 22.

${ }^{17}$ Ibíd., 11.

${ }^{18}$ Geertz, La interpretación de las culturas, 122.
} 
impuestas implícitamente en un mundo con una estructura particular" ${ }^{19}$; y en este contexto de casas-templos, las mujeres cumplieron un rol relevante de expansión.

En otros términos, la eficacia e impacto de los templo-casa parten tanto de las posibilidades de adaptabilidad en un contexto adverso en términos de sociabilidad como el de entonces, como también en su particular inscripción en un entramado simbólico muy propio de la iglesia cristiana, y más específicamente pentecostal, donde las "iglesias caseras" (pequeños grupos, con una estructura flexible y liderazgo dinámico) rememoran a las primeras comunidades cristianas en el Nuevo Testamento, como un especie de retorno a un estado de origen y pureza" ${ }^{20}$.

\section{Tiempo cúltico: música y prédica}

Los padres de Hidelbrando "eran evangélicos y el cine era para ellos una de las cosas mundanales que la religión abominaba. Lo mismo que asistir a los bailes, oír canciones en la radio, poner discos en la victrola, tocar la guitarra, o leer libros que no trataran de la Palabra del Señor" ${ }^{21}$.

Las prohibiciones que señala el autor eran comunes en casi todas las denominaciones pentecostales del momento; pero la de tocar guitara solo ocurría en la Iglesia Evangélica Pentecostal, dado que otras denominaciones ya habían incluido instrumentos en los ritos cúlticos desde comienzo de la década de los 30 , tal como lo relata Nicomedes Guzmán.

Un aspecto interesante de Rivera Letelier reside en que los sujetos pentecostales son destacados con sus virtudes y sus errores; él no adorna el imaginario pentecostal ni los enloda, sino relata aspectos cotidianos de la fragilidad humana y de las condiciones de precariedad en las que vivían:

Los sábados y domingos, el hermano Tenorio López vendía paquete de sapolio y alfajores de Pica en el centro de la ciudad [...] de todos era sabido que los alfajores no provenían de Pica, sino de una pedestre fábrica de dulces de la calle Adamson. En cuanto al sapolio, de una cueva en uno de los cerros del Salar del Carmen, lugar donde el Hidelbrando del Carmen lo había acompañado junto a sus hijos [...] en esa actividad participaba toda la familia [...] la propaganda decía: Sapolio harneado: limpia hasta los pecados. ${ }^{22}$

\footnotetext{
${ }^{19}$ Ibíd.

${ }^{20}$ Panotto, "Pentecostalismos y construcción de identidades sociopolíticas", 73-96.

${ }^{21}$ Rivera, Himno del ángel parado en una pata, 21.

${ }^{22}$ Ibíd., 78.
} 
El autor muestra el carácter ambiguo de la conversión del sujeto pentecostal, que al estar en una denominación pentecostal donde no existía el acompañamiento instrumental de la música, de algún modo se constituía en un paliativo para quienes venían del mundo de la juerga. En cambio, en la Iglesia Evangélica Pentecostal se trataba de música a secas. Por ello, los hombres, en algunos momentos vuelven, de tiempo en tiempo, a esas nostalgias: "en el mercado, el hermano Tenorio le contaba a Hidelbrando las historias de los tiempos cuando él 'era del mundo"'23.

Dado que "los símbolos religiosos apuntan no solo hacia la existencia del bien sino también hacia la del mal y hacia el conflicto entre ambos" ${ }^{24}$, el mal es relativizado y a su vez complejizado, al existir un mal concebido por la sociedad y otro por el individuo; uno por la iglesia y otro por el individuo. Por esa existencia paradójica y contradictoria del ser humano es imposible que el pentecostalismo tenga un control extensivo e intensivo en el individuo, como destacaron algunas investigaciones que consideraban dicha religión como secta.

El discurso pentecostal empujaba a los creyentes a olvidar el pasado, a sepultarlo en la memoria y resaltar el presente, en especial el futuro como el único tiempo “contenido en una concepción de los propósitos de Dios"25. No obstante, los relatos muestran la capacidad del sujeto converso de resistir la institucionalización y vivificar el pasado con la "picardía" que emerge en contextos patriarcales.

[El] hermano Tenorio aún mantenía su viejo acordeón en un rincón de la casa... el hermano se dejaba tentar por la nostalgia de sus tiempos de músico y [...] se ponía a entonar bajito alguno de aquellos viejos corridos mexicanos que aún le aleteaban vivos en su memoria. ${ }^{26}$

Esta disección entre música sacra y profana la hacía tajantemente la Iglesia Evangélica Pentecostal, pero no los otros pentecostalismos. Sin embargo, el carácter contrafactum de la música pentecostal es descrito por otros autores ${ }^{27}$. Mientras el énfasis separa la música del mundo y la música del Señor, en la práctica esta separación resulta ambigua. Por el contrario, ese carácter profano de la música pentecostal fue justamente lo que atrajo a tantos conversos, sobre todo la música ranchera pentecostal.

\footnotetext{
${ }^{23}$ Ibíd., 78.

${ }^{24}$ Geertz, La interpretación de las culturas, 121.

25 Ibíd., 95.

${ }^{26}$ Rivera, Himno del ángel parado en una pata, 83.

${ }^{27}$ Guerra, "La música en el movimiento Pentecostal (1909-1936): el aporte de Willis C. Hoover y de Genaro Ríos Campos”.
} 
Rivera Letelier muestra también que la conversión no era un proceso de un borrado de memoria, sino de autocontrol, autoselección, en concordancia con la nueva institucionalidad de la conversión. Este proceso relacional de la conversión es significativo, dado que hasta no hace mucho tiempo se proponía que la conversión pentecostal fuera un proceso de ruptura radical.

La Iglesia Evangélica Pentecostal "llegaba hasta el extremo de no usar instrumentos musicales de ninguna clase para acompañarse en sus litúrgicos cánticos de alabanzas a Dios" ${ }^{28}$. En cuanto la "cosmovisión se hace emocionalmente convincente al presentársela como una imagen de un estado de cosas peculiarmente bien dispuesto para acomodarse a tal estilo de vida" ${ }^{29}$, la música permite la transmisión o reafirmación de esa cosmovisión y se considera de mayor pureza en cuanto menor acompańamiento instrumental; y por medio de la música se transmitía la cosmovisión bíblica para reforzar el ethos pentecostal sobre las formas de vestir y sus consecuencias.

No obstante, existían otras denominaciones pentecostales, como la Iglesia Metodista Pentecostal, IMP, que permitían música en sus templos, así como en las calles y los hogares. Ambas denominaciones pentecostales (Iglesia Evangélica Pentecostal e Iglesia Metodista Pentecostal) competían permanentemente ${ }^{30}$. Esto lo muestra el autor:

...un domingo llegó una misión evangélica de otra iglesia llegó a predicar a la oficina y recorrió las calles cantando con gran alboroto de instrumentos [...] Embelesado por la música de las mandolinas, guitarras, banjos, panderos, $\mathrm{y}$ triángulos los que más escandalizó a su madre fue que se acompañara alegremente con palmas. ${ }^{31}$

Dicha competencia, cuyo origen encontramos en 1932 (año del cisma pentecostal, del cual nació la Iglesia Evangélica Pentecostal de la Iglesia Metodista Pentecostal), se constituye en un recurso para predicar y crecer, para mostrar la eficiencia del carisma ${ }^{32}$.

La seriedad religiosa también fue parte del ethos pentecostal, esto es, "el tono, el carácter y la calidad de su vida, su estilo moral y estético, la disposición de su ánimo”,

\footnotetext{
${ }^{28}$ Rivera, Himno del ángel parado en una pata, 22.

${ }^{29}$ Geertz, La interpretación de las culturas, 89.

${ }^{30}$ Donoso-Maluf, "Comunitarización competitiva: auge de la Iglesia Metodista Pentecostal de Chile", 229-258.

${ }^{31}$ Rivera, Himno del ángel parado en una pata, 22.

${ }^{32}$ Donoso, "Comunitarización competitiva: auge de la Iglesia Metodista Pentecostal de Chile, 229-258; Mansilla, Leiva y Muñoz, "Pospentecostalismo: del fundacionalismo al posfundacionalismo pentecostal chileno", 172-185.

${ }^{33}$ Geertz, La interpretación de las culturas, 121.
} 
en donde los pentecostales fueron conocidos por su adustez ${ }^{34}$. Esto lo registra el autor al decir:

...y él [nińo] casi nunca había visto reír a su padre. A veces pensaba que desnudar los dientes en una sonrisa significaba para él una actitud vituperable. Aunque, ahora que se acordaba, no lo había visto reír a carcajadas, reír hasta derramar dos lágrimas. ${ }^{35}$

No obstante, el ethos se inserta en una cosmovisión caracterizada por la visión nostálgica y melancólica frente a la vida, por un lado, y las condiciones de vida y la religiosidad ascética, por el otro, que limita la manifestación de alegría. ¿Cómo lograban resolver el ascetismo social frente a una religión popular festiva con la cual competían? Lo hacían mediante cultos catárticos y extáticos que brindaban libertad al creyente. Y dado que "se trata de la actitud subyacente que un grupo tiene ante sí mismo y ante el mundo que la vida refleja” ${ }^{36}$, el sentimiento dramático y melancólico se hizo parte de la cultura religiosa pentecostal.

$\mathrm{Al}$ entender que la cosmovisión "es una concepción de la naturaleza, de la persona, de la sociedad" ${ }^{37}$, la prédica era fundamental: todo creyente pentecostal era un predicador. En este sentido se asignó importancia primordial, por lo menos hasta la década de los 90, al "cuerpo de ciclistas", un recurso muy significativo en una sociedad en transición entre lo agrario y lo urbano. Este grupo permitía conectar y apoyar a las iglesias pequeñas, predicar en las calles y evangelizar en los lugares apartados.

[Era] un grupo de misioneros ciclistas [que] venía sembrando la semilla del Evangelio desde Arica y esa tarde se unieron a la predicación de la calle que la iglesia realizaba todos los domingos [...] esa tarde se había predicado la palabra más inspirados que nunca [...] y, bajaron por la calle Peñuelas, encaminados directamente hacia la iglesia en una gran procesión interminable, el "venid, pecadores Jesús os salvará", marcial himno de guerra de los predicadores, resonaba en el aire glorioso y espeluznante. ${ }^{38}$

La exclamación del relato "predicamos más inspirado que nunca" se refiere a la cantidad de personas que invadían las calles predicando, para luego cantar en conjunto el himno "Venid pecadores a Jesús" y llegar en una columna, casi marchando al templo.

\footnotetext{
${ }^{34}$ Véase a Vergara, El protestantismo en Chile.

${ }^{35}$ Rivera, Himno del ángel parado en una pata, 48.

${ }^{36}$ Geertz, La interpretación de las culturas, 121.

${ }^{37}$ Ibíd.

${ }^{38}$ Rivera, Himno del ángel parado en una pata, 60.
} 
Estas performances emocionaban incluso a los vecinos, que siempre se molestaban con la bulla en los templos.

Los pentecostales tenían una estrategia bastante particular para saber el mensaje que debían predicar, lo cual Rivera Letelier explica de la siguiente manera:

...el Pastor en esos momentos, detrás del púlpito, con la Biblia cerrada entre las manos, invitaba a orar para pedir al Señor su santo mensaje a través de las Escrituras (el versículo sobre el cual se posaba su pulgar izquierdo al terminar de orar constituía el mensaje del Señor). Mientras los hermanos con los ojos cerrados y las manos alzadas al cielo pedían el mensaje a viva voz. ${ }^{39}$

Gran parte del pastorado pentecostal ingresaba al liderazgo religioso siendo adulto y muchas veces analfabeto. Ello era coincidente con la baja escolaridad nacional, donde saber leer y escribir era lo básico y necesario para el trabajo manual. Así, "la religión, es en parte un intento de conservar el caudal cultural" ${ }^{0}$, en este caso, el caudal cultural campesino, subproletario e indígena, característica de una cultura oralista y poco escritural.

\section{La construcción de lo masculino y lo femenino}

La generalidad de las investigaciones ha sido mostrar que los pentecostales enfatizan en la sumisión de los sujetos, en especial de las mujeres. No obstante, Rivera muestra cómo las mujeres jóvenes se las arreglaban para adecuar las exigencias de indumentarias de la iglesia con vestidos ajustados y mostraban sensualidad y erotismo en la danza.

\section{La construcción de lo femenino}

Uno de los roles más importantes de la mujer -más que la danza o la oración- era profetizar:

...en las noches de culto, la hermana Jovita veía a la paloma de Espíritu Santo revoloteando alrededor del púlpito. Veía portentosos ángeles de seis alas paseándose con espadas de fuego por los pasillos de la nave, cuidando celosamente a los siervos de Dios. ${ }^{41}$

Ella veía visiones. Discernía los "espirituales" de "los carnales". Su palabra tenía mucho peso, y en ocasiones era inclusive más importante que la de los pastores y predicadores. Por eso siempre se buscó ponerle coto.

\footnotetext{
${ }^{39}$ Ibíd., 64.

${ }^{40}$ Geertz, La interpretación de las culturas, 121.

${ }^{41}$ Rivera, Himno del ángel parado en una pata, 134.
} 
Desde la boca de los hermanos que oraban con devoción, la hermana Jovita Esperanza veía emerger un humito blanco que se elevaba directamente hacia el cielo; en cambio, de la boca de los que mientras oraban se ponían a pensar en asunto que no tenían nada que ver con los comercios divinos, la hermana Jovita Esperanza veía un humito negro. ${ }^{42}$

Dormir era un claro indicio de carnalidad y mundanidad: muchas veces quienes se quedaban dormidos eran ungidos, o bien se levantaban los ancianos y expulsaban el "demonio del sueño" del creyente que osaba dormir en un culto o una vigilia; por más cansado que saliera del trabajo, no había excepción ni justificación.

En las creencias y prácticas religiosas, la relación entre ethos y cosmovisión es relevante: “...el ethos se convierte en algo intelectualmente razonable al mostrárselo como representante de un estilo de vida idealmente adaptado al estado de cosas descrito por la cosmovisión”" ${ }^{3}$. En este sentido, los pentecostales mantenían férreo control sobre cuestiones éticas, en especial sobre los estereotipos del cuerpo femenino.

Para la década de los 60, todas las iglesias evangélicas, incluso el catolicismo, mostraban una tenaz vigilancia sobre la vestimenta de las mujeres. En este contexto, "las hermanas jóvenes no podían emperifollarse demasiado. Los aros, los collares, los anillos, y todo ese paramento de baratija con que se arremingaban las mujeres del mundo, a ellas, como hijas de Dios, les estaba terminantemente prohibido”44.

En ese entorno de miseria, las mujeres se sometían a tales exigencias y daban testimonio de que los recursos invertidos en bisutería les servían para comprar alimentos. En general, "no podían pintarse los ojos ni los labios, ni esmaltarse de rojo las uńas; tampoco les estaba permitido teñirse el cabello, o llevarlo suelto sobre la cara, o usarlo demasiado corto. Todo su afeite se reducía a lavarse la cara con agua de la llave y jabón de olor" ${ }^{45}$.

Este discurso podía inclusive ser coincidente con ciertas propuestas del feminismo, pues el pentecostalismo de entonces, para cuestionar la cosificación de la mujer o la mujer objeto, reinventó una dicotomía entre "mujer carnal” y “mujer espiritual”. Esta última debía romper con la cosificación del cuerpo femenino mediante el abandono de las costumbres en torno de la estética y las vestimentas, las cuales se entendían como una imposición desde el mundo.

\footnotetext{
${ }^{42}$ Ibíd.

${ }^{43}$ Geertz, La interpretación de las culturas, 89.

${ }^{44}$ Rivera, Himno del ángel parado en una pata, 22.

${ }^{45}$ Ibíd.
} 
$\mathrm{Al}$ entender que "los símbolos sagrados tienen la función de sintetizar el ethos de un pueblo y su cosmovisión, el cuadro que ese grupo se forja de cómo son las cosas en la realidad, permiten un orden" ${ }^{46}$; se podría afirmar que el ethos pentecostal sobre la corporalidad femenina estaba influenciado por la cosmovisión bíblica y la religión de los pobres y condicionado por el entorno social y cultural de la época. Eso era aplicable a la mujer adulta y anciana, pero las mujeres jóvenes se las ingeniaban para buscar espacio de libertad y elección en la forma de vestir.

Rivera Letelier también destaca las habilidades musicales de las mujeres, así como su posibilidad de crear música o readaptar himnos y coros -lo cual se consideraba algo inspirado-, y transformarlos en parte del himnario de la iglesia:

La hermana Orlanda poseía el don más hermoso que se conocía en la Iglesia Pentecostal: el de recibir himnos, dados en música y letra, directamente del Espíritu Santo. Y todos los himnos y coros que ella, de pronto, caída en trance en medio de un avivamiento, rompía a entonar con su bello gorjeo de ángel operático, eran incluidos en la himnología de la iglesia y entonados luego con recogimiento y regocijado fervor en todas las congregaciones del país. ${ }^{47}$

Aunque a la mujer se le prohibió el púlpito, se le dio espacio de creatividad en la palabra escrita de los himnos y en la poesía, algo que Rivera Letelier nos señala.

De igual modo, la mujer tenía como tiempo-espacio el rol de la intercesión, es decir, de orar por los demás. Aun cuando como mujeres pentecostales oraban por pobres y ricos, proletarios y patrones, el pentecostalismo era una religión de pobres y proletarios $y$, por tanto, nunca entraría por sus puertas un rico o un patrón, porque incluso en los espacios sagrados existe la diferenciación y separación de clases. En este sentido "su madre, la que vestida de gracia y con gran regocijo espiritual gustaba de dar su testimonio de salvación en las reuniones de los días viernes, contando sobre lo dura de corazón que había sido al principio para aceptar el bendito nombre de Jesús”48.

Una vez más aparece el rol del relato vivo, el testimonio dinámico y siempre cambiante en el cual la mujer, aunque con espacios y roles limitados, se podía construir en sujeto y por tanto sujeto de su propio relato. Aquí "la esencia de la acción religiosa consiste en estar imbuida de cierto complejo específico de símbolos para brindar autoridad persuasiva ${ }^{49}$. Estos símbolos se desgajan de la Biblia: de ella interpretan las expectativas sobre lo femenino y lo masculino.

\footnotetext{
${ }^{46}$ Geertz, La interpretación de las culturas, 89.

${ }^{47}$ Rivera, Himno del ángel parado en una pata, 82.

${ }^{48}$ Ibíd., 29.

${ }^{49}$ Geertz, La interpretación de las culturas, 107.
} 
Rivera Letelier, a pesar de que la mujer está muy presente en diversas actividades laborales y eclesiásticas, en su trabajo muestra también su visión sexista: “...la hermana Olimpia, nueva en los caminos del Señor, era una joven de una belleza carnal que alborotaba visiblemente al rebaño masculino de la iglesia. Tenía un andar sinuoso de félido hembra y una lánguida mirada a media asta" ${ }^{50}$.

Aunque el texto dé cuanta de la visión de un niño-adolescente, la mirada está mediada por un adulto-escritor que resalta la belleza de la mujer en relación con lo blanco: por ejemplo, cuando dice que Hidelbrando había visto por una ventana a la hermana Olimpia "en pańos menores [...] vio la blancura sublime de sus carnes" 51 . Esta belleza-blancura se debe más bien a la piel "bien cuidada" porque, a diferencia de las otras mujeres, la "hermana Olimpia" era joven y esposa de un aviador, mientras que las otras mujeres eran esposas de mineros. De igual modo, se trataba de una mujer convertida recientemente y, por tanto, su forma de vestir aún dependía de sí misma y no de la iglesia.

Al ser una iglesia pequeña, las mujeres con buena situación económica, en comparación con las mujeres pobres, tenían mayor autonomía para vestirse y acceso a comprar ropa nueva. Su vestimenta no era holgada como la de las mujeres institucionalizadas. Por ello, la mujer se constituye en objeto de la mirada de los hombres de la iglesia, lo cual es percibido por las ancianas de la congregación, quienes harán entrar pronto a la mujer al camino de la consagración, modelando su forma de vestir y de caminar, para que no se constituya en tentación masculina.

...en vez de la severa moña evangélica, la hermana llevaba su largo cabello castaño sensualmente caído sobre un solo lado de la cara. Sus faldas, ceñidas más de la cuenta a sus caderas ondulantes, eran motivo de escándalo y murmuración entre las santas ancianas de la iglesia. ${ }^{52}$

Eran las mujeres quienes controlaban la forma de vestir de las otras mujeres jóvenes, no los hombres. La forma de vestir, de caminar, de mirar, de saludar, todas son formas aprendidas y ritualizadas. En "esta clase de ritual, es donde los estados anímicos y motivaciones que los símbolos sagrados suscitan en las personas y donde las concepciones generales del orden se refuerzan entre las mismas personas" ${ }^{33}$. Esto es, las mujeres institucionalizadas son las encargadas de institucionalizar a las mujeres jóvenes o recién convertidas.

\footnotetext{
${ }^{50}$ Rivera, Himno del ángel parado en una pata, 17.

${ }^{51}$ Ibíd.

52 Ibíd.

${ }^{53}$ Geertz, La interpretación de las culturas, 107.
} 
Rivera Letelier hace una caracterización de la mujer pentecostal de la pampa (Salitrera Algorta) y de la mujer pentecostal urbana (Antofagasta), en tono poco apropiado, al caracterizar a la mujer por su cuerpo, al decir que "la belleza pura de las hermanas más jóvenes lo tenía encandilado" ${ }^{54}$. Es notorio que la juventud y la niñez en la pampa duraran poco, tanto por el ímpetu del sol como por las condiciones miserables del trabajo y la vivienda, tal como lo han destacado otros literatos ${ }^{55}$.

[A] muchas de ellas alguna vez las había visto danzar tomadas del Espíritu Santo: con sus rostros iluminados de la gracia de Dios y como dotadas de finas alas invisibles, las había visto desplazarse a través de la nave en bellos escorzos de danza angélica, y las había hallado sencillamente gloriosa. ${ }^{56}$

Obviamente, esta concepción de belleza -"bellos escorzos" o "danzas angélicas"-, que de algún modo el pentecostalismo imponía a las mujeres, con la exigencia de usar vestimentas holgadas, largas y sin bisutería, apuntaba a centrar la mirada en el espíritu y no en el cuerpo.

Las mujeres pentecostales adultas intentaban evitar que la mirada se centrara en sus cuerpos, sobre todo cuando salían a predicar u orar por los enfermos. Usar ropas ceñidas era la libertad que detentaban las mujeres jóvenes solteras, recién conversas, o recién casadas.

De la misma manera, Rivera Letelier etiqueta y hace parangón de lo femenino en cada momento en función de su cuerpo, lo feo-bonito, blanco-moreno, joven-vieja, pueblo-ciudad, india-blanca: "las hermanas de la congregación del centro [Antofagasta], todas de ojos claros, cabellos rubios y piel más blanca que la nieve, eran para él seres casi sublimes" ${ }^{57}$. Dicha etiqueta pasa de una visión sexista a una racista, al equiparar la belleza con blancura y "rubiedad".

[Sus] cuerpos espigados, exhalando sutiles aromas de agua colonia, no tenían nada que ver con aquellas santas ancianas abolivianadas, de excrecentes lunares pilosos, papadas de abadesa y aliento podrido, que conformaban la exigua congregación del culto de la oficina Algorta. ${ }^{58}$

La concepción de belleza de Rivera es campechana y anacrónica, al usar metáforas como "cuerpos espigados", o "las santas ancianas" para referirse a una iglesia pequeña y a la escasez de juventud y niñez.

\footnotetext{
${ }^{54}$ Rivera, Himno del ángel parado en una pata, 29.

${ }_{55}$ Sabella, Teitelboim, Guzmán, y antes que ellos, Baldomero Lillo.

${ }^{56}$ Rivera, Himno del ángel parado en una pata, 29.

${ }^{57}$ Ibíd., 30.

${ }^{58}$ Ibíd.
} 
Las salitreras ya estaban en decadencia en los años 60. En el contexto del campamento minero, por cada dos hombres había una mujer; por tanto, incluso en espacios religiosos, la mujer era un sujeto-objeto deseado. Además, en los campamentos salitreros había una notable población indígena (quechua y aymara), tanto chilena como boliviana. No obstante, en un contexto antiindígena, el aymara era generalizado o confundido con el boliviano, por lo general, sinónimo de indio pobre.

En este sentido es llamativo, cuando Rivera califica a las mujeres pentecostales ancianas como "abolivianadas" y les atribuye "excrecentes lunares pilosos", "papadas de abadesa" y "aliento podrido", cómo cae en lo grotesco y grosero, en su concepción de lo femenino, al estigmatizar a las mujeres indígenas aymaras como bolivianas, como indígenas, pobres y extranjeras.

También aparecen otras diferenciaciones: mujeres evangélicas y mujeres no evangélicas, o mujeres santas y mujeres profanas, por ejemplo, al describir a una mujer prostituta del campamento minero:

...apenas tenía pechos. Pero sus largas piernas asociándole doradas por la abertura generosa del camisón, era lo que hacía delirar a Hidelbrando. Esas bellas piernas de bronce [...] él las hallaba comparables solo a las piernas infinitas de Rosita Quintana. ${ }^{59}$

Es la obsesión de lo sagrado por lo profano: el religioso que se obsesiona con la prostituta porque, en los espacios sagrados, la exposición de los cuerpos femeninos estaba prohibida, incluso en los lechos conyugales. Hidelbrando, "como siempre también, entró como pisando en el aire, con la misma unción y recogimiento con que se entra a un recinto sagrado a mitad de la liturgia" ${ }^{60}$.

El cuerpo femenino de una prostituta genera ese nivel ensimismamiento y recogimiento que Rivera asimila a un espacio sagrado, es decir, a la trasposición espacial donde lo profano se vuelve sagrado y donde el adolescente entra al espacio profano de la prostituta con el mismo sentimiento de recogimiento que el sagrado-eclesiástico. Se trata de una disputa entre dos campos que nunca están totalmente bifurcados, ya que "los símbolos sagrados dramatizan no son solamente valores positivos, también dramatizan valores negativos" ${ }^{\prime 1}$, donde la experiencia religiosa y la experiencia erótica son asimiladas.

Rivera destaca otra diferenciación entre "chica evangélica" y "chica del mundo". El control de las mujeres adultas de las iglesias se reflejaba en las enseñanzas de las

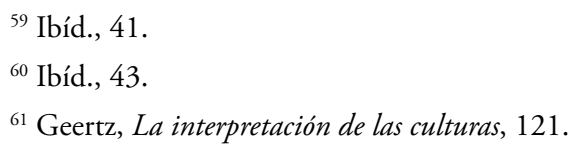


madres en esa época en la que afirmaban que "las mujeres eran las conquistadas", y no al revés. Esta norma no escrita era un problema para los hombres adolescentes, tímidos e introvertidos, a quienes les eran más convenientes las mujeres atrevidas, con "sus cabellos rubios graciosamente revueltos, su blusa blanca atada en un ligero nudo por sobre la maravilla de su ombligo el minúsculo trozo de género rojo de su falda volandera [que] le daban un inquietante aire de hembrita felina, de pequeña mujer fatal"'62.

En cambio, las mujeres jóvenes evangélicas tapaban sus cuerpos de cuello a tobillos, y por ello Rivera dice:

...acostumbrado de toda la vida a ver a las hijas de las hermanas vestidas, la mayoría de ellas, de toscas polleras largas y el pelo invariablemente reprimida a una montaña apercollada con fuertes nudos de elástico, la visión de la nínfula le resultó sencillamente fascinante, turbadora: reveladora. ${ }^{63}$

La vestimenta y el uso del cuerpo como símbolos de piedad religiosa muestran que dichos "símbolos apuntan no solo hacia la existencia del bien sino también hacia la del mal y hacia el conflicto entre ambos" ${ }^{64}$.

Aun cuando el pentecostalismo daba voz y espacio de participación a las mujeres en contextos de invisibilización y silencio, su relación pública con la iglesia se trataba de una extensión del rol doméstico: mientras el hombre monopolizaba la palabra en el púlpito, la mujer limpiaba y adornaba el recinto, como en este caso, en donde "su madre, siempre la veía bordando pañitos y encarrujando rosas de papel para adornar el púlpito" ${ }^{65}$.

\section{La construcción de lo masculino}

Rivera Letelier muestra también las angustias de los jóvenes pentecostales para conquistar a las mujeres; ellos disponían de recursos sociales y simbólicos para cortejar a las jóvenes evangélicas, pero no a las mujeres "no evangélicas", porque el pentecostalismo elaboraba distintos recursos de construcción social de la masculinidad:

...esa noche evidenció algo que ya venía elucubrando hacía rato en la soledad de su cuartucho: que para conquistar a una niña perteneciente al mundo de

\footnotetext{
${ }^{62}$ Rivera, Himno del ángel parado en una pata, 61.

${ }^{63}$ Ibíd.

${ }^{64}$ Geertz, La interpretación de las culturas, 121.

${ }^{65}$ Rivera, Himno del ángel parado en una pata, 29.
} 
los gentiles era necesario saber y dominar tres cosas elementales: bailar, nadar $\mathrm{y}$ andar en bicicleta. Y él era torpe en las tres. ${ }^{66}$

Bailar estaba terminantemente prohibido. Nadar también era difícil, pues ni siquiera los hombres podían mostrar sus cuerpos semidesnudos. En cambio, sí podían ser diestros en las bicicletas, porque cabe recordar que los pentecostales entrenaban a los hombres en bicicletas desde nińos, para la preparación del ministerio llamado "cuerpo de ciclista": los predicadores en pedales.

La trasposición del espacio - en cuanto profanación de lo sagrado y sacralización de lo profano- resulta interesante en Rivera Letelier, quien logra que los espacios sean dúctiles, ambiguos y cambiantes según las experiencias y sentimientos de los sujetos masculino o femenino:

Mientras ella lo besaba infinitamente, ascendió y estuvo en cuerpo y alma en aquella célica morada que cantaban los versos del himnario. Vio sus muros hecho de jaspes y de cristal, sus pies hollaron el fino polvo de oro de sus calles radiantes, y en los prados en donde el león y el ciervo pacen juntos, a la orilla del río cuyas aguas cristalinas nacen del mismísimo trono de Dios, junto a serafines y querubines pulsando liras y arpas dulces en un eterno banquete de amor, se vio alabando y glorificando por los siglos de los siglos el bendito nombre del Cordero santo. ${ }^{67}$

Amor y muerte, tierra y cielo, lo humano y lo divino, logran unirse en estas experiencias, pese a la miseria y la pobreza que rodeaba a los habitantes; pero Rivera se diferencia de la literatura social de Sabella o Teitelboim, e incluso de Guzmán, de quien hay una notoria influencia en Rivera; este no se centra en la angustia, lo oscuro o la miseria, sino en la mirada eudemonista del niño-adolescente.

De las experiencias reconfortantes y compensatorias de lo humano que el pentecostalismo forzaba evitar, se trata de cómo la masculinidad se fortalece en el encuentro erótico con lo femenino. $Y$ desde la mirada del niño-adolescente no veía la muerte ni la perdición, como habitualmente lo resaltaba el discurso de los adultos: “...en la iglesia jamás habías sido tomado por la gracia del Espíritu Santo, pero no tuvo ninguna duda de que algo así se debía sentir”"68. De este modo, religión y erotismo y erotismo y religión convergen en el encuentro sexual.

Las experiencias presexuales del niño-adolescente las describe como experiencias carismáticas y célicas. Un hombre las podía vivir dentro o fuera de la iglesia.

\footnotetext{
${ }^{66}$ Ibíd., 65.

${ }^{67}$ Ibíd., 74.

${ }^{68}$ Ibíd.
} 
Por tanto, "el flamígero coraje" consiste en realizar incursiones solitarias al campamento enemigo y a estremecerse pensando en dar algún golpe maestro" ${ }^{6}$. El campamento enemigo de los pentecostales eran los espacios del mundo (bailes, fiestas, circos, fútbol, etc.). Los pentecostales decían que la amistad con el mundo implicaba enemistad con Dios. Por ende, la amistad con las "mujeres del mundo" significaba enemistad con "las mujeres de la iglesia".

También se da cuenta de la diferencia en el trato del padre hacia un hijo o una hija:

...la jovialidad del hermano Tenorio se trocaba en grave puritanismo cuando de su única hija mujer se trataba; jamás le sonreía ni la titubeaba como a sus hijos varones [...] la hacía regresar enseguida a casa, indicándole que no era bien visto que una señorita cristiana se entretuviera sola en la calle. ${ }^{70}$

El extremo de la diferencia estaba en que el papá trata de "usted" a su hija. Casi nunca andaba sola, porque no era bien visto; aunque en el pentecostalismo una mujer casada sí podía andar sola, esto no era lo recomendable. Podía hacerlo si se trataba de trabajos religiosos: ir sola a la iglesia o visitar a alguien, siempre y cuando fuese algo vinculado a la iglesia; de otro modo no era recomendable, porque se consideraba una pérdida de tiempo.

Un aspecto constitutivo de la cultura pentecostal fue poner nombres bíblicos a los hijos e hijas. De hecho, esta era una de las formas de reconocer a un pentecostal:

...habían tenido siete hijos: seis varones y una mujer [...] bautizó a cada uno de sus hijos con el nombre de un libro bíblico. De tal manera que los varones se llamaban Nehemías, Esdras, Jonás, Miqueas, Job y Josué; y a la niña, que era la primogénita, le había puesto Génesis. ${ }^{71}$

Aunque el nombre de Hildebrando no está asociado con lo evangélico, al autoidentificarse como parte de dicha expresión religiosa se generaba un doble matiz: admiración y rechazo. Esto se muestra en el siguiente relato:

...una vez que Hildebrando del Carmen le contó a la mujer que atendía las mesas que él era hijo de padres evangélicos, esta, sonriéndole con dulzura, le acarició la barbilla y le dijo que se le notaba en los ojos, pues tenía una transparente mirada de nińo bueno. ${ }^{72}$

\footnotetext{
${ }^{69}$ Geertz, La interpretación de las culturas, 94.

${ }^{70}$ Rivera, Himno del ángel parado en una pata, 61.

${ }^{71}$ Ibíd., 84.

${ }^{72}$ Ibíd., 103.
} 
Por otro lado, también estaba la discriminación y violencia que afectaba a los niños evangélicos en las escuelas y barrios: “...canuto de mierda, le dijo fuerte, para que lo oyeran los demás niños de la patota” ${ }^{73}$. Tal es una expresión común en Chile para insultar a los evangélicos, y en el pasado era manifestación de prejucio, discriminación y estigmatización, conocida como "canutofobia”" ${ }^{4}$. Esta aparece en otras expresiones del libro: en la burla, "al ver que entre los floreros y los parámetros del púlpito iba una jaula de pájaro vacía, ironizó en alta voz alta que seguramente los canutos llevaban ahí al Espíritu Santo"75.

Puede sobrellevarse la burla al individuo, pero nunca el insulto a los símbolos que sustentan su fe y creencias, pues esta es una violencia simbólica:

...el hombre depende de símbolos, y esa dependencia es tan grande que resulta decisiva para que el hombre sea una criatura viable, de manera que la más remota indicación de que no puede habérselas con uno u otro aspecto de la experiencia le causa la más viva ansiedad. ${ }^{76}$

Tales elementos también se evidencian por medio de mitos urbanos, resaltados entre los pentecostales y destacados en la obra de Rivera:

1. No orar por los alimentos. Esto se relacionaba con la concientización sobre la importancia de la acción de gracias:

Al dar la primera mascada al pan... se acordó de la bendición... algo que ya no hacía... le recordó una historia que le contó con su padre, "sobre aquel pastor evangélico al que le habían intentado envenenar con la comida y que se había salvado gracias al conjuro divino de la bendición. Pues, mientras en voz alta y con los ojos cerrados el diácono bendecía el alimento, el poder de Dios hizo que la sopa comenzara a borbotear en el plato y a derramarse lentamente sobre la mesa, convertida en una repulsiva espuma sucia. Turbado con aquél recuerdo $[\ldots]$ inclinó la cabeza, cerró los ojos y balbuceo una rápida oración. ${ }^{77}$

Este rumor era permanentemente relatado a los niños y conversos recientes para internalizar la acción de gracias de manera coercitiva. Esto se trata de lo que Geertz

\footnotetext{
${ }^{73}$ Ibíd., 75.

${ }^{74}$ Véase a Mansilla, La cruz y la esperanza, la cultura del pentecostalismo chileno en la primera mitad del siglo $X X$.

${ }^{75}$ Rivera, Himno del ángel parado en una pata, 108.

${ }^{76}$ Geertz, La interpretación de las culturas, 96.

${ }^{77}$ Rivera, Himno del ángel parado en una pata, 158.
} 
denomina como "la 'circunspección moral', es decir la experiencia de culpabilidad frente a lo divino" 78 .

2. Dormirse en el culto. Era necesario un recurso de control atemorizante ante la extensión de los cultos -a veces vigilias (reuniones que se extendían hasta la madrugada, con el propósito de orar y cantar)-, máxime cuando las personas pasaban de su trabajo al culto:

Para él era algo tan irreverente dormirse en el templo y jamás había incurrido en el pecado de dar siquiera una pestañada en la casa del Señor. Aunque había noches en que el fuego del Espíritu Santo se enfriaba hasta hacer surgir el bostezo, nunca había cometido el sacrilegio de ponerse a cabecear en las bancas de la iglesia. Menos aún desde la noche en que la hermana Jovita Esperanza había visto a un diablito desnudo sentado sobre la cabeza de un hermano que dormía; el pequeño diablito, con cara de travieso, mantenía sus muelles talones apoyados justo en los parpados del hermano. ${ }^{79}$

Estaba presente la idea de controlar el cuerpo y las emociones para lograr suficiente atención hacia lo cúltico, junto a la "tranquilidad desapasionada" necesaria para conservar el equilibrio ante "cualquier circunstancia"

\section{El problema del mal y el dolor}

¿Cómo enfrentar, interpretar o responder al problema del mal, por ejemplo, a las enfermedades? El pentecostalismo es una religión con un discurso que compite externamente con el catolicismo popular y el protestantismo, e internamente con otros grupos pentecostales; por tanto, la oferta de sanación, las ritualidades y el acompañamiento debían ser efectivos: un proceso de recuperación de la salud significaba la posibilidad de convertir a una familia y a potenciales predicadores con el testimonio; y cuando se trataba de la muerte, lo mismo: el cielo era la oferta de todos los grupos pentecostales, y cada grupo pintaba el cielo de una belleza sin igual. Sin embargo, el énfasis estaba puesto en los rituales de agonía, mortuorios y funerarios.

\section{Enfermedad, sanidad y testimonio}

Uno de los recursos más atractivos para las personas en situación de vulnerabilidad y pobreza fue la oferta pentecostal de sanación y la interpretación sobre las

\footnotetext{
${ }^{78}$ Geertz, La interpretación de las culturas, 94.

${ }^{79}$ Rivera, Himno del ángel parado en una pata, 136.

${ }^{80}$ Geertz, La interpretación de las culturas, 94.
} 
enfermedades ${ }^{81}$. El llamado "problema del mal consiste en formular desde el punto de vista de la cosmovisión la verdadera naturaleza de las fuerzas destructivas que moran en la persona y fuera de ella, de manera tal que sea posible llegar a una especie de acuerdo con esos fenómenos ${ }^{82}$. Entre los ritos estaban la imposición de manos, la intercesión comunitaria y el acompañamiento. "Una de las hermanas que conformaba el grupo de Dorcas ${ }^{83}$ había contado que el Señor, por medio de su infinito amor y misericordia, le había extirpado un tumor canceroso que los médicos terrenales habían declarado incurable" ${ }^{84}$.

Así como los "ritos y la creencia religiosa se enfrentan y se confirman recíprocamente" ${ }^{15}$, en este caso la imposición de manos dio lugar al testimonio de sanación. Esto apunta a un elemento fundamental de la cosmovisión y práctica pentecostal: el acceso al testimonio brinda el derecho u oportunidad de hablar en medio de la comunidad, rito practicado fundamentalmente por las mujeres.

El testimonio consiste en una práctica discursiva muy frecuente en la comunidad, que era enseñada a los conversos a partir de un conjunto determinado de mecanismos e inclusive el uso de términos específico, por medio de los cuales la iglesia daba cuenta sobre las acciones de Dios en sus vidas. El testimonio cumple una función sociológica fundamental, en especial como epicentro hermenéutico tanto del texto bíblico como de cualquier dogma, creencia o imaginario particular. Los testimonios no solo eran herramientas pedagógicas y teológicas, sino también espacios y tiempos sociopolíticos en cuanto daban lugar a la participación de las mujeres, en medio de una sociedad que las silenciaba ${ }^{86}$.

De igual modo, en la medida en que el testimonio era más dramático y espectacular, los conversos adquirían prestigio, privilegios y posibilidades para transitar por diversos espacios de autoridad al interior del grupo de mujeres llamadas Dorcas. Por tanto, la participación de las mujeres en los distintos ritos (testimonios, imposición de manos, catarsis, etc.) presentaba como estos como símbolos sacralizados de la necesidad de lo femenino en los espacios de la pobreza y la miseria; solo de ese modo

\footnotetext{
${ }^{81}$ Véase a Mansilla, La cruz y la esperanza. La cultura del pentecostalismo chileno en la primera mitad del siglo $X X$.

${ }^{82}$ Geertz, La interpretación de las culturas, 121.

${ }^{83}$ Para conocer más sobre las Dorcas, ver a Orellana, "La Iglesia Pentecostal: comunidad de mujeres".

${ }^{84}$ Rivera, Himno del ángel parado en una pata, 15.

${ }^{85}$ Geertz, La interpretación de las culturas, 121.

${ }^{86}$ Orellana, "La Iglesia Pentecostal: comunidad de mujeres", 119-132.
} 
-como dic Geertz-, "se producen diferencias empíricas entre la actividad religiosa o de la experiencia religiosa" ${ }^{77}$.

Las mujeres eran las principales captoras de nuevas conversas y las encargadas de llevar y convertir su familia al pentecostalismo. ¿Por qué las mujeres eran efectivas en captar nuevas conversas? Porque iban a predicar a hogares donde había cesantías, personas enfermas, alcoholismo y violencia intrafamiliar. Así, los recursos sociales administrados por ellas mujeres eran aplicados en tales contextos sociales, donde se convertían, producían y reproducían, tanto dentro como fuera del templo.

El ethos "se hace intelectualmente razonable al mostrarse que representa un estilo de vida implícito por el estado de cosas que la cosmovisión describe”88; por tanto, la imposición de manos y el testimonio fueron dos ritos que se hicieron parte del ethos pentecostal y que brindaron un gran espacio a la mujer, a veces acompañado de la glosolalia y la danza.

El proceso de sanación acontecía en medio de un conocido ritual que se relacionaba con los símbolos pentecostales: “...el maravilloso milagro [de sanidad] había ocurrido durante una noche de oración y vigilia en su ciudad. Mientras la ungían en el nombre de Dios, ella, en visión espiritual, vio acercarse al Médico celestial en la figura de un anciano de túnica blanca" ${ }^{89}$. Esto se inserta en la cosmovisión pentecostal del milagro, del poder interventor del Espíritu Santo, y "se hace emocionalmente aceptable al ser presentada como una imagen del estado real de cosas del cual aquel estilo de vida es una auténtica expresión" ${ }^{\prime 0}$.

Primero se produce en el contexto del ritual (canto, oración y vigilia). Una vez preparado el ambiente emotivo viene la segunda parte, en la que "los ancianos de la iglesia imponen las manos sobre la doliente", y en ese momento inicia el proceso de catarsis y éxtasis del doliente para generar el perfomance de la sanación. Después viene el proceso de "visión sanación", es decir, cuando la doliente recibe la visita del Médico celestial, quien

...con una voz llena de dulzura le preguntó: “¿Crees?” Y cuando ella respondió llorando: "Sí, creo, Señor", el anciano le tocó con la punta de las yemas el pecho canceroso y fue como si unas pinzas al rojo vivo la hubiesen desgarrado por dentro, extirpándole lo malo... haciéndola sentirse completamente sana de toda enfermedad. ${ }^{91}$

\footnotetext{
${ }^{87}$ Geertz, La interpretación de las culturas, 95.

${ }^{88}$ Ibíd., 121.

${ }^{89}$ Rivera, Himno del ángel parado en una pata, 15.

${ }^{90}$ Geertz, La interpretación de las culturas, 121.

${ }^{91}$ Rivera, Himno del ángel parado en una pata, 15.
} 
El proceso de sanación representa un hecho dramático e inolvidable que daba lugar a otro elemento central de esta ritualidad: el testimonio, en el que el relato sobre lo acontecido se repetía constantemente por ańos, y era activo, porque iban cambiando los detalles, pero la estructura testimonial era la misma, acompañada siempre de la emoción:

...y hasta el día de hoy, glorificaba la hermana con los ojos borrados en llanto, a sus 73 ańos cumplidos, después de 25 años transcurridos la operación divina, completamente sana brincando como un corderito en la manada, aún vivía para testificar y glorificar por siempre el bendito nombre del Salvador. ${ }^{92}$

Resulta interesante advertir que el rito es dinámico, el relato es vivo y el sujeto activo. Esto permitía que la comunidad brindara a los sin voz el derecho a hablar, la posibilidad de ser escuchados y hacer del testimonio una acción en la que "los aspectos más afectivos son una cuestión de afirmar que en última instancia los sufrimientos son tolerables" ${ }^{\prime 2}$.

Las conversiones detentan una estructura narrativa similar. En el caso del pentecostalismo se trataba, por parte del creyente, de la necesidad de búsqueda de ayuda y asistencia al templo. En cierto modo, la conversión es "esa búsqueda de claridad y esa acometida de la angustia metafísica, que se dan cuando los fenómenos empíricos amenazan permanecer intransigentemente oscuros" ${ }^{94}$.

Antes de iniciar el proceso de sanación se conminaba al creyente a realizar una promesa inquebrantable, que partía de la conversión familiar al pentecostalismo, del compromiso con la evangelización (es decir, un trabajo de invitación a que otros y otras se conviertan y también se sumen a la iglesia) y de la "consagración" (compromiso con la iglesia, sus bases teológicas y las prácticas de sus fundamentos éticos) del enfermo-víctima:

...la hermana Orlanda [...] enfermó grave cuando nińa [...] sus padres decidieron como último recurso acudir al templo de la Iglesia Evangélica Pentecostal. Y allí, llorando ambos de rodillas ante el púlpito, mientras la iglesia temblaba con los cánticos de alabanzas al Señor, habían encomendado a su hija en cuerpo y alma en las manos de Dios, que él hiciera su santa voluntad... y sanó... desde entonces sus padres se habían convertido al Evangelio y habían permanecido en él hasta el mismo día de sus muertes. ${ }^{95}$

\footnotetext{
${ }^{92}$ Ibíd.

${ }^{93}$ Geertz, La interpretación de las culturas, 100.

${ }^{94}$ Ibíd., 98.

${ }^{95}$ Rivera, Himno del ángel parado en una pata, 81.
} 
Estos elementos dan cuenta de la delimitación de fronteras de los procesos identitarios, en los que se ve la fuerza que tiene una religión para prestar apoyo a valores sociales, pues es "en la capacidad de sus símbolos para formular un mundo en el cual tales valores, así como las fuerzas que se oponen a su realización, son elementos constitutivos fundamentales ${ }^{96}$.

El proceso de consagración del enfermo-víctima se relataba (como testimonio) una y otra vez en el seno del hogar y de la familia, y el consagrado se constituía en un escogido de Dios, resaltándosele como un privilegiado de Dios:

Orlanda era la que más se veía trabajando para la viña del Señor: visitaba a los enfermos en su casa, ayudaba en lo que podía a los necesitados, consolaba con palabras de afecto a los afligidos, dirigía el coro de la iglesia, enseñaba a las hermanas Dorcas y era que en los servicios a la calle predicaba el mensaje de Cristo. ${ }^{97}$

De hecho, las mujeres que daban testimonio de haber recibido milagros de sanación o la rehabilitación de su esposo del alcohol resignificaban sus vidas. trabajando en el templo, predicando, visitando enfermos y haciendo oraciones y ayunos: eran, precisamente, las que más trabajaban en el templo. Se trata de "las significaciones generales en virtud de las cuales cada individuo interpreta su experiencia y organiza su conducta ${ }^{98}$.

Por lo general, la persona que buscaba ayuda era la mujer, quien encontraba espacio de trabajo y participación al interior de la comunidad, de acuerdo con el relato. Por ello -tal como señala Zicri Orellana-, el pentecostalismo era una comunidad de mujeres ${ }^{99}$; ellas visitaban a los enfermos para acompañarlos en distintas actividades (orar por ellos, interceder en comunidad, cooperar con alimentos y ropa, incluso cuando la persona enferma se trataba de una mujer y madre de la casa); ayudaban a hacer aseo y cocinar en la casa para atender a los niños. Ese acompañamiento no lo hacía ningún otro grupo religioso.

Uno de los espacios de participación más importantes de las mujeres era la prédica en la calle, donde ejercían el derecho a la palabra pública y expresaban los dramas de sus vidas pasadas y presentes. Así, el pentecostalismo se une "a tradiciones

\footnotetext{
${ }^{96}$ Geertz, La interpretación de las culturas, 122.

${ }^{97}$ Rivera, Himno del ángel parado en una pata, 83.

${ }^{98}$ Geertz, La interpretación de las culturas, 118.

${ }^{99}$ Orellana, "La Iglesia Pentecostal: comunidad de mujeres", 119-132.
} 
religiosas que afirman enérgicamente la proposición de que la vida hiere, lastima; y en alguna tal proposición es virtualmente glorificada" ${ }^{100}$.

La oferta de sanidad era un elemento fundamental para los pentecostales, lo que se constituyó en el ethos más importante de la comunidad. Se oraba por la sanidad en cada reunión: en el culto general, en el de Dorcas, los jóvenes y en los encuentros con niños (Escuela dominical). Al interior del templo, quienes más realizaban el rito de la imposición de manos eran los hombres:

...el hermano Natalio, junto a otros ancianos de la congregación, cada domingo ungía y bendecía a los enfermos en la iglesia. También se ungía, a la distancia, a aquellos enfermos que se hallaban postrados en sus casas o en sala de algún hospital; solo bastaba que alguien lo pudiera y les diera el nombre. ${ }^{101}$

Este proceso estaba mediado por la música, recurso fundamental, sobre todo, en el proceso interpretación de la enfermedad y sanación. Tal como destaca Geertz para otras realidades religiosas,

...el punto culminante del cántico y todo el proceso de cura puede compararse con una osmosis espiritual en la cual la enfermedad del hombre y el poder de la deidad penetran la membrana ritual en ambas direcciones, de suerte que la primera queda neutralizada por el segundo. ${ }^{102}$

El don de sanidad o el talento musical eran para todos: hombres y mujeres, niños y adultos. Tener el don de sanación, por lo general, era el requisito para ser pastor, pues representaba la forma más eficaz de ganar conversos. No obstante, dicho don no siempre era un recurso benéfico, ya que a veces, si lo tenía el ayudante del pastor y no el pastor mismo, se traducía en una lucha por la legitimidad del poder y de la autoridad de la iglesia, y esto inducía al cisma, en el que usualmente el pastor ayudante era expulsado o se producía un conflicto local que terminaba en la migración de la mitad de la congregación, para dar comienzo a una nueva denominación ${ }^{103}$.

El rito de sanidad conminatorio era bastante simple: "No tienes arte ni parte", se decía a toda voz; "por tanto yo te conmino, espíritu inmundo, en el santo nombre de Jesús, a salir en el acto del cuerpo de este pequeño hijo de Dios, vencido para siempre por su sangre bendita que nos lava y limpia de todo pecado. Amén” ${ }^{104}$. No sabemos

\footnotetext{
${ }^{100}$ Geertz, La interpretación de las culturas, 99.

${ }^{101}$ Rivera, Himno del ángel parado en una pata, 104.

${ }^{102}$ Geertz, La interpretación de las culturas, 101.

${ }^{103}$ Un historial de los cismas de los pentecostales y su posterior nacimiento de distintas denominaciones actuales la podemos encontrar en Vergara, El protestantismo en Chile.

${ }^{104}$ Rivera, Himno del ángel parado en una pata, 104.
} 
quién dijo estas primeras palabras, pero sí existe registro de que se utilizaban en todas las iglesias pentecostales. Además, el sentimiento y la emoción que las acompañaba era similar: “...él sintió que se electrificaba el alma, se elevaba unos cuantos milímetros de las tablas del suelo" ${ }^{105}$. El poder que brindaba al conminador también era indescriptible.

De este modo, el pentecostalismo implicaba también otorgar poder simbólico a los oprimidos. Todo comenzaba y terminaba cantando. La música y el canto producen un "efecto reconfortante que estriba en última instancia en poder dar a la persona enferma un vocabulario que le permita comprender la naturaleza de su mal y referirla a un mundo más amplio" ${ }^{106}$; pero también implicaba brindarle un vocabulario apropiado al conminador.

\section{El morir y la muerte}

El proceso de morir y la muerte también eran una diferenciación en el pentecostalismo. En distintos grupos indígenas había indicios descifrables de la muerte, y por tanto existían especialistas en la decodificación de sus signos. En el caso que aquí analiza el autor, dice:

...la muerte de su madre había sido profetizada en una noche de gran avivamiento espiritual en la iglesia, a los doces días de haber llegado a vivir a Antofagasta [...] el Espíritu Santo tomó como instrumento a la hermana Sixta Montoya, que tenía el don de la profecía, para dar sus mensajes a la congregación. ${ }^{107}$

Hasta la década de los 80 , las profecías sobre la muerte -en el pentecostalismofueron de igual modo recursos muy buscados, sobre todo para los enfermos graves y adultos mayores. No obstante, lo que destaca Rivera Letelier es para personas sanas, y eso era considerado como milagro y privilegio, tanto para la profetiza como para la persona escogida para morir. Todos sabemos que vamos a morir; el privilegio es saber cuándo será. Luego de la profecía, era muy significativo el acompañamiento, sobre todo cuando se trataba de una mujer-madre que dejaba niños, lo cual se constituía en una muerte dolorosa ${ }^{108}$. De este modo, "el problema de la significación, como uno de los factores que empujan a los hombres a creer en divinidades" ${ }^{109}$, consistía en encontrarle significado a la pérdida prematura de una madre.

\footnotetext{
${ }^{105}$ Ibíd.

${ }^{106}$ Geertz, La interpretación de las culturas, 101.

${ }^{107}$ Rivera, Himno del ángel parado en una pata, 27.

${ }^{108}$ Véase a Mansilla, La buena muerte. La cultura del morir en el pentecostalismo.

${ }^{109}$ Geertz, La interpretación de las culturas, 105.
} 
El proceso de morir y la muerte constituyen otro problema irresoluto e insoslayable del mal. En vista de "la idoneidad de recursos para suministrar una serie viable de criterios éticos y de guías normativas que gobiernen nuestras acciones" ${ }^{110}$, entre los recursos entregados se ubicaban las profecías, que no eran expresadas de manera directa y cruda, sino también bajo el arrobar de la música cúltica:

....aquella noche, la hermana Sixta Montoya [...] poseída por el Espíritu, danzó desplazándose a lo largo y ancho de toda la nave [...] sus manos elevadas al cielo y sus ojos en blanco. Luego cayó de rodillas frente al púlpito, hablando y predicando en lenguas [...] Después del Espíritu Santo la hizo caer en trance y entonces comenzó a profetizar. ${ }^{111}$

Rivera Letelier presenta también el proceso del rito de la profecía: posesión de la profetiza; danza, éxtasis, arrodillarse en el púlpito y disposición corporal de conducto. "Por su intermedio fue que el Señor le había hablado a su padre diciéndole que se preparara, que una gran prueba le estaba por enviar desde alto. Que debía ser fuerte y valeroso que confortara su espíritu con ayunos y oraciones y que leyera Job” ${ }^{112}$. En este caso, la profecía fue entregada al esposo de la mujer y padre del niño, considerada la pérdida o muerte como "gran prueba" y como tal debía preparar con las ritualidades consideradas significativas para los pentecostales para recibir fuerza, valor y consuelo.

La profecía en medio del culto también cumplía la función de que la comunidad religiosa acompañara al "viudo antes de la viudez" y al "huérfano antes de la orfandad"; "a los tres días después, su madre, una mujer de corazón ancho, joven aún, de salud y ánimo jocundos, sucumbió al veneno de una minúscula araña de los rincones" ${ }^{113}$. La muerte de una madre siempre es dolorosa en todas las culturas. Por tanto, el acompañamiento comunitario fue fundamental:

...las hermanas que le acompañaron hasta que exhaló su último suspiro en la sala del hospital, decían que su madre se había muerto cantando [...] cuyas sublimes estrofas decían que los muertos en el Señor se encontrarían un día reunidos en el cielo, a orillas del río de aguas cristalinas que nacían del trono de Dios. ${ }^{114}$

\footnotetext{
${ }^{110}$ Ibíd., 102.

${ }^{111}$ Rivera, Himno del ángel parado en una pata, 28.

${ }^{112}$ Ibíd.

${ }^{113}$ Ibíd.

${ }^{114}$ Ibíd.
} 
El título del himno justamente se llama "Nos veremos en el río":

¡Oh, sí! Nos congregaremos

en célica, hermosisima ribera

del rio de la vida verdadera

que nace del trono de Dios ${ }^{115}$.

Rivera Letelier muestra la vida y muerte de un pentecostal, que -pese a su compromiso religioso adusto- vive y muere cantando. La música, con o sin acompañamiento instrumental, es fundamental para la cultura pentecostal. Además, el himno cantado por la madre del niño, quien muere cantando, alude a la belleza del cielo, como símbolo de significación de una muerte prematura cuyas promesas eran anunciadas por este himno, que además decía:

... antes de llegar al rio,

nuestras cargas al dejar,

libres todos quedaremos

por la gracia del Señor".

Y “todo el mundo le hablaba: el Señor la llamó a su presencia; el ángel pasó lista y ella respondió; la mamita ya se encuentra gozando en la Nueva Jerusalén”"116. Aquí aparecen las distintas metáforas mortuorias: muerte-llamado, pasar lista y el cielo como Nueva Jerusalén. Interesante y más desconocida es la imagen de "el ángel pasó lista", que alude al soldado que lee un listado de los soldados que son llamados a misiones espaciales. La muerte es "uno de esos caos que amenazan irrumpir en el hombre: en los límites de su capacidad analítica, en los límites de su fuerza de resistencia y en los límites de su visión moral"117. De ahí la importancia de la comunidad. No solo es difícil morir solo: también es difícil vivir el proceso de pérdida solo.

La comunidad religiosa se encargaba de velar por los niños huérfanos, fundamentalmente para que siguieran asistiendo al culto. Obviamente la muerte es dolorosa, y más aún para los niños:

...pese a todo, tres días después de enterrar a su madre, una radiante mañana de domingo en la escuela dominical, luego que la esposa del pastor le hiciera

\footnotetext{
${ }^{115}$ Este himno, de origen norteamericano, fue creado por Robert Lowry en 1864. Su título en inglés es "Shall We Gather at the River".

${ }^{116}$ Rivera, Himno del ángel parado en una pata, 29.

${ }^{117}$ Geertz, La interpretación de las culturas, 97.
} 
recitar de memoria las bienaventuranzas junto a los demás niños, había hecho un espontaneo gesto de reconciliación con Dios. ${ }^{118}$

Por consiguiente, Rivera Letelier alude a la idea de "reconciliación con Dios", quizás porque el niño cuestionaba la muerte de su madre. ¿Por qué ella y no otra? ¿Por qué tan joven? $\mathrm{O}$ ¿̨por qué por una arańa y no otro medio? Como sea, muestra que el culto le brindó las condiciones para asumir y aceptar la pérdida.

Llevado tal vez por el estado anímico en que se hallaba, y por la exaltación que le producía el corito de recoger la ofrenda: "Dios bendice al que da con alegría [...] dejó caer en el talego todas las monedas que había ganado en la confección y venta de volantines durante los quince días que llevaba viviendo en la ciudad. Se sintió liviano como un ángel'. ${ }^{119}$

Una vez más trae a colación el rol de la música, para motivar y también para consolar: la música como recurso paliativo. De este modo,

...los símbolos religiosos suministran una garantía cósmica no solo de su capacidad de comprender el mundo sino también, de dar precisión a los sentimientos que experimenta, de dar una definición a las emociones, definición que les permite experimentarlas con tristeza o alegría, hosca o altivamente. ${ }^{120}$

Otro aspecto significativo es la representación del cadáver y de la muerte que los pentecostales tenían y tienen, que difiere totalmente del catolicismo: “...los evangélicos pentecostales jamás cargaban luto por la muerte de ningún ser querido [...] Y en la oficina Algorta a su madre se le habían muerto, uno tras otro, durante un periodo de diez años, siete angelitos de meses" ${ }^{121}$.

Se muestra la alta tasa de mortalidad infantil, pero el pentecostalismo, igual que la cultura popular, consideraba la muerte de un niño como la muerte del angelito, cuyo velatorio debe ser alegre. También se muestran las ritualidades mortuorias de los niños, que no son distintas a los ritos mortuorios del angelito realizados por el catolicismo, tanto en el norte como en el sur de Chile. "Su último hermanito muerto, para velarlo, lo habían disfrazado de angelito. Lo adornaron con alas recortadas en papel de estańo y lo sentaron en una pequeña sillita de paja puesta sobre una mesa arrimada a la pared"122.

\footnotetext{
${ }^{118}$ Rivera, Himno del ángel parado en una pata, 34.

${ }^{119}$ Ibíd., 146.

${ }^{120}$ Geertz, La interpretación de las culturas, 101.

${ }^{121}$ Rivera, Himno del ángel parado en una pata, 103.

${ }^{122}$ Ibíd., 146.
} 
Al niño lo vestían de blanco, le ponían alas y luego lo sentaban. Ante tales aspectos, el niño no parecería muerto sino alguien quieto observando, un ángel. Y Rivera Letelier lo describe:

...parece un muñeco de cera; los ojos abiertos se le ven deslucidos y tiene toda la cara blanca de polvos de arroz; en sus manitas yertas, entrelazadas a la fuerza, sostiene un clavel celeste confeccionado en papel de seda. Su figura sonámbula se recorta contra una sábana blanca constelada de estrellitas y medias lunas de papel plateado. ${ }^{123}$

El velatorio era más una celebración que se realizaba con abundante comida (al ser evangélicos, sin alcohol). Se trataba de velatorio lúdico. Esta creencia ayudaba a ponderar la alta mortalidad infantil de la época. La idea era quitar a la muerte su carácter terrible, sin profanarlo. A lo sacro se le agrega lo lúdico porque "en todas partes, lo sacro entraña un sentido de obligación intrínseca: no solo alienta la devoción, sino que la exige, no solo suscita asentimiento intelectual, sino que impone entrega emocional ${ }^{124}$; por consiguiente, al profanar lo sacro, al enfrentar la pérdida de modo lúdico, encontraban recursos y ritos que transformaban la pérdida en algo más llevadero. Así mismo, están las muertes absurdas, que obviamente no dejan de ser trágicas:

Luego de la trágica muerte del anciano que hacía de guía en la congregación local [...] el anciano había muerto arrollado por el tren de pasajero cuando, traslucido de gracia y debilitado hasta lo angélico, venía de vuelta de uno de sus rigurosos retiros espirituales; retiros que, entre ayunos y oraciones a voz viva, llevaba a cabo periódicamente en la soledad de los cerros circundantes. ${ }^{125}$

Muestra la vida rígida de un pastor (Probando) pentecostal, quien ante su soledad se entrega a los ayunos, oraciones y vigilias, igual que los antiguos cristianos anacoretas del yermo, quienes seguramente ante su soledad, sordez y vejez anhelaban la muerte, también influidos por los himnos y cánticos celestiales.

Otro aspecto que Rivera destaca es cómo el pentecostalismo reacciona frente a las animitas católicas, como forma de deslegitimar la religiosidad popular católica:

El hermano Tenorio López había sepultado a la orilla de un camino rural a un despanzurrado burro negro. Y sobre el montículo de tierra, que cercaron de pequeñas piedras en orden, le alzaron una cruz que fabricaron ahí mismo con palos de las cercas. A los pocos días, a una anciana achacosa que atinó a pasar por el camino, pensando tal vez que se trataba de una animita nueva, se le ocurrió encenderle una vela, rezarle un par de avemarías y pedirle el favor

\footnotetext{
${ }^{123}$ Ibíd.

${ }^{124}$ Geertz, La interpretación de las culturas, 118.

${ }^{125}$ Rivera, Himno del ángel parado en una pata, 107.
} 
de un milagro. Luego nomás había comenzado a correr el rumor de lo buena y milagrosa que era la Animita del camino. Y antes de que cantara un gallo, ya le habían construido una gruta y dos templetes de lata que se llenaron de cirios encendidos, tarros con flores y toda una constelación de placas de agradecimientos por los favores concedidos. ${ }^{26}$

Las animitas son formas del catolicismo popular para enfrentar el dolor de la muerte trágica, que competían con la oferta pentecostal; no obstante, eran alternativas válidas. Dado que "los símbolos sagrados dramatizan, no son solamente valores positivos, también dramatizan valores negativos" ${ }^{127}$.

Estos tres mitos estaban presentes con sus dimensiones comunitarias sagradas: el espacio privado, el eclesiástico y el barrial, donde lo religioso cobra relevancia. Dichas espacialidades muestran instancias de visibilidad de ciertos elementos distintivos del pentecostalismo, y también -como otro conjunto de dimensiones de construcción identitaria- son marcos de disputa de sentido respecto de imaginarios y prácticas sociales, y también religiosos, como era el catolicismo popular.

\section{Bibliografía}

Archivo Nacional de Chile. "21 de diciembre de 1907. Matanza de la Escuela de Santa María de Iquique en 1907”. Archivo Nacional de Chile, http://www. archivonacional.cl/616/w3-article-37531.html?_noredirect=1 (consultado el 4 de diciembre de 2018).

Blaustein, Daniel. "Incursiones en un texto amistoso: Himno del ángel parado en una pata, de Hernán Rivera Letelier”. Escritos 34 (2006): 143-161.

Bravo Campos, Luis Alex. "Literatura y contraemplazamientos: vigilancia, heterotopía, traición y alteridad literaria en Chile... a partir de la ficción narrativa de Hernán Rivera Letelier". Tesis para optar al grado de Doctor en Literatura Latinoamericana, en la Universidad de Concepción, Chile, 2013.

Donoso-Maluf, Francisco. "Comunitarización competitiva: auge de la Iglesia Metodista Pentecostal de Chile”. Perfiles latinoamericanos 13 (1998): 229-258.

Geertz, Clifford. La interpretación de las culturas. Barcelona: Gedisa, 2003.

González, Sergio. Hombres y mujeres de la pampa. Tarapacá en el ciclo de expansión del salitre. Santiago: Centro de Investigaciones Diego Barros Arana, 2002.

${ }^{126}$ Ibíd., 193.

${ }^{127}$ Geertz, La interpretación de las culturas, 121. 
Guerra, Cristian. "La música en el movimiento Pentecostal (1909-1936): el aporte de Willis C. Hoover y de Genaro Ríos Campos". Sendas (2009), http://www.corporacionsendas.cl/investigacion_musical.php (consultado el 25 de noviembre de 2018).

Guzmán, Nicomedes. La sangre y la esperanza. Santiago: LOM, 1999.

Maíz, Claudio. "La narrativa de Rivera Letelier: los signos de la escasez y la abundancia compensatoria”. Universum 17 (2002): 157-169.

Mansilla, Miguel. La buena muerte. La cultura del morir en el pentecostalismo. Santiago: UNAP-RIL, 2016.

. La cruzy la esperanza. La cultura del pentecostalismo chileno en la primera mitad del siglo XX. México: MANDA, CIAL-UNAM, UNAP, 2014.

. "Pentecostalismo y ciencias sociales reflexión en torno a las investigaciones del pentecostalismo chileno (1968-2008)". Cultura y religión 3/2 (2009): 21-42.

Mansilla, Miguel, Sandra Leiva y Wilson Muñoz. "Pospentecostalismo: del fundacionalismo al posfundacionalismo pentecostal chileno". Cinta moebio 59 (2017): 172-185.

Mansilla, Miguel, y Luis Orellana. "Haciendo memoria de líderes religiosas olvidadas. El reconocimiento póstumo del trabajo de las pastoras en el pentecostalismo chileno". Sociedad y religión 23/40 (2013): 77-113.

Orellana, Zicri. "La Iglesia Pentecostal: comunidad de mujeres". Cultura y religión 3/2 (2009): 119-132.

Ostria, Mauricio. “La identidad pampina en Rivera Letelier”. Acta literaria 30 (2005): 67-79.

Panotto, Nicolás. "Pentecostalismos y construcción de identidades sociopolíticas". Desafios 26/2 (2014): 73-96. DOI: dx.doi.org/10.12804/desafios26.02.2014.03

Revista Fuego de Pentecostés 98 (1936). Santiago de Chile: Iglesia Evangélica Pentecostal.

Rivera, Hernán. Himno del ángel parado en una pata. Santiago: Alfaguara, 1996.

Vergara, Ignacio. El protestantismo en Chile. Santiago: E. del Pacifico, 1962. 